\title{
Substâncias que agem: uma análise dos discursos sobre os hormônios e o movimento pela humanização do parto
}

Substances that act: an analysis of discourses on hormones and on the movement for the humanization of childbirth

\section{Sara Sousa Mendonça}

Doutora em Antropologia pelo Programa de Pós-Graduação em Antropologia da Universidade Federal Fluminense (PPGA/UFF).

\section{Resumo}

Este artigo tem a proposta de construir uma interpretação a respeito da representação dos hormônios no discurso biomédico incorporado no cotidiano, em relação ao dualismo cartesiano e à forma peculiar de representação deles dentro do discurso das ativistas pelo parto humanizado. O dualismo cartesiano é entranhado nas representações sobre o corpo tanto no senso comum quanto no discurso biomédico, se constituindo como um dos maiores desafios a serem transpostos para a realização de uma antropologia do corpo. Assim, minha proposta aqui é justamente tomá-lo como objeto, a partir de suas representações e desdobramentos em determinados contextos, não o tratando de forma estática, mas buscando dar conta de seu movimento e alterações e como estes podem encaminhar tanto para a sua permanência, quanto constituírem linhas de fuga.

Palavras-chave: Hormônios, Dualismo Cartesiano, Emoções, Gênero, Parto.

\section{Abstract}

This article proposes the construction of an interpretation regarding the representation of hormones in the biomedical discourse incorporated in everyday life, in relation to Cartesian dualism and the peculiar form of their representation within the discourse of activists for humanized birth. The Cartesian dualism is entrained in the representations of the body as much in common sense as in the biomedical discourse, becoming one of the biggest challenges to be overcome for the making of an Anthropology of the Body. So my proposition here is precisely 
to take it as an object of study, taking its representations and developments in certain contexts as a starting point, not in a static way but trying to handle its movement and changes, thinking how they can refer both to his stay as constitute lines of escape.

Keywords: Hormones, Cartesian Dualism, Emotions, Gender, Delivery/Birth.

Minha proposta neste artigo é construir uma interpretação a respeito da representação dos hormônios no discurso biomédico incorporado no cotidiano, em relação ao dualismo cartesiano e à forma peculiar de representação deles dentro do discurso das ativistas pelo parto humanizado. $\mathrm{O}$ dualismo cartesiano é entranhado nas representações sobre o corpo, tanto no senso comum quanto no discurso biomédico, se constituindo como um dos maiores desafios a serem transpostos para a realização de uma Antropologia do Corpo. Assim, minha proposta aqui é justamente tomá-lo como objeto, a partir de suas representações e desdobramentos em determinados contextos, não o tratando de forma estática, mas buscando dar conta de seu movimento e alterações e como estes podem encaminhar tanto para a sua permanência quanto constituírem linhas de fuga.

Como material etnográfico, utilizarei dados de minha pesquisa de campo a respeito do movimento pela humanização do parto (MENDONÇA, 2013), obtidos em palestras e encontros de médicos e de ativistas pelo parto normal; serão utilizados também dados da pesquisa de campo virtual, como depoimentos publicados em sites, blogs e fóruns na internet por profissionais da saúde, mães/gestantes, ativistas e, eventualmente, pais. Para análise das representações hormonais para um público mais amplo, utilizarei matérias de jornais e revistas. 


\section{O DUALISMO CARTESIANO E O DESENVOLVIMENTO DA ANTROPOLOGIA DO CORPO}

Meu objetivo neste trabalho não é realizar uma longa revisão bibliográfica dos autores que trabalharam com o tema da corporeidade, mas situar as dificuldades de sua produção a partir desse dualismo, pois no decorrer do trabalho abordarei contextos relacionados a biomedicina em relação a essa dualidade e quero evidenciar o tamanho enraizamento desta questão no pensamento ocidental, que mesmo uma disciplina como a antropologia, que se propõe a tratar da alteridade, se debateu (e debate) para conseguir se desvencilhar.

O tardio desenvolvimento de uma antropologia do corpo é uma questão destacada em textos introdutórios da área. Por que se tardou tanto desde a elaboração da disciplina até que a dimensão corporal fosse levada em conta? Situando como texto inaugural o ensaio sobre as técnicas corporais de Marcel Mauss $(2003)^{1}$, na década de 1930, temos ainda que os desdobramentos a partir desde tardam - com o perdão do trocadilho - a tomar corpo. Autores como Citro (2010) e Csordas (2008) apontam as causas para isto.

A primeira delas seria a tradição filosófica ocidental de separação entre corpo e mente/alma/razão, identificada como dualismo cartesiano, no qual há uma hierarquia entre estas instâncias, que privilegia a razão, construindo uma noção de pessoa moderna como racionalidade individual desencarnada, com as instâncias relacionadas ao corpo (emoções, sensações e paixões) vistas enquanto opostas e enganadoras da razão. Segundo Citro, não cabe "culpabilizar" Descartes pela persistência dessa dualidade, mostrando como tal separação já se fazia presente na filosofia ocidental desde os gregos (Platão e Aristóteles) e cristãos (Santo Agostinho e Tomás de Aquino), e que o próprio Descartes ao final de sua vida reviu parte de suas opiniões a respeito, afirmando que a alma estaria verdadeiramente unida ao corpo, mantendo, porém, o dualismo

\footnotetext{
Csordas e Citro trazem considerações sobre o artigo inaugural de Mauss (2003) a respeito de como ele próprio reproduz em seu olhar o dualismo cartesiano. Csordas destaca como relevante que o autor tenha elaborado de forma independente seu ensaio sobre a noção de pessoa do trabalho a respeito das técnicas corporais, já Citro observa as diferentes formas de construção dos textos, principalmente o recurso do autor à sua experiência pessoal para desenvolver sua argumentação sobre as técnicas corporais, denotando que o acesso ao corpo só seria possível por meio da experiência.
} 
enquanto uma prescrição metodológica. Observar o impacto de uma obra como essa ao longo do tempo é interessante de uma perspectiva da história das ciências: mesmo que ao final de sua vida ele tenha modificado seu pensamento, o impacto de sua obra permaneceu sendo o dos escritos anteriores, possivelmente pois estes eram mais facilmente incorporados ao pensamento ocidental.

Ao lado dessa tradição de pensamento, Citro coloca como causa para o esquecimento do corpo o desenvolvimento do capitalismo, que possibilitou a constituição do corpo-máquina (como Descartes havia imaginado), o processo de construção de corpos dóceis, estudado por Foucault (1982). A análise do processo civilizador, de Elias (1994), também é fundamental para que se compreenda as representações dos corpos na modernidade, mostrando como a noção de autodomínio do indivíduo sobre seu corpo e emoções é visto como traço valorizado da pessoa no processo de consolidação da burguesia.

Desse conjunto de processos deriva que os corpos não foram meramente esquecidos, mas confinados enquanto perigosos e potencialmente úteis, uma vez que disciplinados. Diversas oposições hierárquicas derivam da corpo/ mente, como razão/emoção, cultura/natureza, teoria/empiria e uma fundamental, destacada por autoras feministas como Butler (2003), masculino e feminino, colocando o corpo feminino no lugar daquele que mais necessitaria de enclausuramento.

Mas então como estudar o corpo sem imprimir uma visão etnocêntrica ocidental? A solução proposta por Csordas busca elaborar no conceito de embodiment um paradigma não dualista da corporeidade, no qual busca articular os conceitos de pré-objetivo, de Merleau-Ponty (2011) e o de habitus, de Bourdieu (1983). No paradigma da corporeidade que Csordas propõe o corpo é um ponto de partida metodológico, antes de um objeto de estudo, sendo um campo indeterminado a ser definido pela experiência perceptiva e os modos de estar e se engajar no mundo. Através de uma análise da percepção (pré-objetivo) e da prática (habitus) busca colapsar a distinção convencional entre sujeito e objeto, investigando como os objetos culturais são produzidos no fluxo e na indeterminação da vida cultural. 
Com esta breve incursão a respeito dos percalços e desafios enfrentados no estudo antropológico dos corpos, objetivei situar o enraizamento do dualismo cartesiano no pensamento ocidental, de modo a poder dar continuidade à proposta do artigo, pensando as articulações entre discursos científicos/ biomédicos ${ }^{2}$, senso comum e seus deslocamentos. Tais deslocamentos se tornam - a meu ver - ainda mais instigantes, pois se dão no bojo de discursos que, diferente do antropológico, nem sempre propõem a superação de tal dualismo.

\section{HORMÔNIOS: SUBSTÂNCIAS QUE AGEM}

Minha proposta de discussão parte de Andrew Strathern (1999) que, ao discutir as formas de tratamento e cura do corpo entre uma população da Melanésia, considera tanto as concepções nativas quanto as introduzidas pelas situações de contato. $\mathrm{O}$ autor propõem um modelo de análise por meio dos termos substância e agência, no qual substância se refere aos fluidos internos (sangues, esperma etc) e aos externos ao corpo (medicamentos tradicionais ou biomédicos). Assim as situações de doença seriam classificadas pela interação entre estes termos. O envenenamento, por exemplo, seria tratado por meio de uma relação de substância sobre substância: no sistema nativo com purificações e extrações, no sistema biomédico ministrando remédios. Os males concebidos como ataques de espíritos ao corpo seriam classificados como agência sobre substância e ataques de espíritos ao espírito concebido enquanto agência sobre agência. Considera ainda a relação substância sobre a agência, nos casos de feitiçarias, na qual uma substância provocaria alucinações, fazendo, portanto, agir.

A partir desta análise do sistema melanésio, considerei instigante pensar a respeito dos discursos sobre os hormônios por meio dos termos substância e agência. Pensando eles enquanto substância, me parece que possuem

\footnotetext{
Utilizo biomédico/biomedicina como o conjunto das representações e práticas de tratamento dos processos de saúde-doença com priorização da ordem biológica, característicos da cultura ocidental moderna (BONET, 2004).
} 
o diferencial de serem internos e produzidos pelo próprio corpo e também concebidos enquanto produtores de agência. Em relação ao dualismo cartesiano, eles modificam ligeiramente a hierarquia entre mente e corpo, pois apesar das fraquezas do corpo como a doença e a debilidade já serem anteriormente consideradas como limitações para o exercício da racionalidade, elas eram encaradas como situações de excepcionalidade. Já com o advento da endocrinologia, no início do século XX, veio se desenvolvendo a percepção de que estas substâncias atuam na vida diária, influenciando o comportamento, as formas de sentir e estar no mundo.

O trabalho etnográfico de Latour e Woolgar (1997), realizado em um laboratório de neuroendocrinologia em meados da década de 1970, propõe uma etnografia da ciência em construção e a escolha por um laboratório dedicado ao estudo e descoberta da ação dos hormônios não é aleatória, no momento se tratava da produção de ponta da biomedicina, tal como é nos dias de hoje a genética, que atrai a atenção de antropólogos da ciência, como Rabinow (1999). O objetivo de Latour (2012) é por meio da teoria ator rede evidenciar a produção dos fatos científicos, sua inserção em uma rede composta por laboratórios, escritórios, fábricas, hospitais, gabinetes de advogados e residências privadas, "todos os lugares onde se faz e desfaz a existência dos hormônios do cérebro" (LATOUR; WOOLGAR, 1997, p. 32).

As representações sobre os genes não serão objeto deste artigo, mas cabe assinalar que elas também podem ser pensadas como relações de substância sobre agência, uma vez que os genes são concebidos não só como indicadores de uma inclinação para tal ou qual doença, mas também como indicadores de formas de ações que podem acarretar doenças. Tal como elaborado pelo geneticista Richard Dawkins, no documentário Sex, death and the meaning of life (2012): o gene que assinalaria a propensão ao câncer de pulmão não se refere a uma fragilidade intrínseca deste, mas atuaria condicionando que seu portador, caso fumante, dê tragadas mais longas, acarretando assim maiores danos aos pulmões.

Ao conceber possibilidades de ações motivadas por essas substâncias é alterada a concepção de homem enquanto animal racional, o aproximando 
dos instintos animais. No início do século XX, com o advento da psicanálise, ocorre um abalo do dualismo cartesiano. Não mais somente o corpo é portador de instâncias enganadoras da razão, mas a própria mente comportaria esta dimensão, com as barreiras para o exercício da plena racionalidade sendo localizadas no inconsciente da mente humana, que deveria ser trazido à consciência, para então ser controlado. Porém a disputa entre a psicanálise e a psiquiatria se desenrolou no sentido de uma maior ênfase nos aspectos fisiológicos, dentro dos quais a descoberta da ação dos hormônios, retornando para o corpo os obstáculos para o exercício da racionalidade.

Tal passagem é abordada por Russo (2004) ao analisar as mudanças ocorridas no campo psiquiátrico nas últimas décadas, a partir das atualizações do Manual Diagnóstico e Estatístico de Transtornos Mentais (Diagnostic and Statistical Manual of Mental Disorders - DSM) no que se referem às sucessivas formas de abordar os desvios ou transtornos da sexualidade. O elemento fundamental dessa mudança é a saída de uma visão psicossocial dos transtornos mentais para uma visão estritamente biológica, que tem como marco a publicação da terceira DSM, em 1980, na qual a hegemonia da psicanálise na psiquiatria termina. Essa DSM é proposta como um manual a-teórico, baseado apenas em princípios de testabilidade e verificação, em que cada transtorno é identificável por critérios acessíveis à observação e empíricos. Tal ênfase na objetividade e empiria se deve à oposição ao modo da psicanálise de analisar processos subjacentes, inferidos pelo clínico e que não são passíveis de observação empírica. A posição a-teórica do manual na realidade era a adoção de uma teoria específica - fisiológica e organicista - trazendo a psiquiatria de volta para a medicina.

Como Russo (2004) e Useche Aldana (2005) apontam, tal processo não pode ser pensado exclusivamente devido às descobertas nessas áreas, estando fortemente atrelado à indústria farmacêutica que possui interesse na conceituação de diversas variações enquanto doenças passíveis de medicalização. A etnografia de Azize (2010) em um congresso de psiquiatria é interessante por evidenciar o quanto esses profissionais são disputados por ações de marketing dessas indústrias. Maluf (2009) reinsere as questões de gênero, sinalizando o 
corpo feminino como o que mais se busca controlar, desde a classificação de mulheres histéricas até os dias de hoje, nos quais elas ainda são maioria dentre os usuários de remédios psiquiátricos, denotando que as frustrações e revoltas de se viver sob a dominação masculina são transformadas/tratadas enquanto doenças mentais.

Assim concluo que essas transformações não abolem o dualismo cartesiano, mas o modificam e mesmo atuam no sentido de reforçá-lo. É atribuído um maior peso ao corpo, ele deixa de ser apenas um enganador da razão para ser concebido enquanto agente. Porém a relação com este corpo não muda, o fato de ele ser capaz de agir e fazer agir só o torna mais perigoso, demandando que o indivíduo racional assuma o cuidado de si e mantenha seu corpo sob controle, agora no nível dos índices hormonais. Como afirma Rohden (2008, p. 134): "Assistimos ao império de um 'corpo hormonal' que parece sobrepor-se a qualquer outra concepção biomédica corrente, pelo menos se considerarmos o sucesso de sua aceitação entre um público cada vez mais amplo".

Os trabalhos de Rohden (2011) a respeito da andropausa e de Manica (2011) sobre os métodos de supressão da menstruação são interessantes para observarmos os discursos que envolvem o controle/cuidado de si em relação aos hormônios.

Iniciando por Manica, a autora analisa como o efeito colateral da pílula anticoncepcional de supressão/irregularidade do ciclo menstrual, inicialmente considerado indesejado, passou a ser positivado na década de 1990, encontrando no médico baiano Coutinho um de seus maiores entusiastas. Para esse médico, a menstruação seria uma sangria inútil. Sua justificativa busca legitimação por meio de uma desassociação entre menstruação e natureza, tanto entre primatas não-humanos como no passado biológico humano, no qual as mulheres pouco menstruariam devido aos sucessivos períodos de gravidez e amamentação, bem como o apontamento que a valorização da menstruação se deu por uma analogia com o hoje desacreditado método das sangrias terapêuticas. Com esta argumentação que busca retirar a menstruação da esfera da natureza, sua proposta de suprimi-la consistiria em um retorno ao natural. Suas falas a respeito da menstruação podem ser lidas à luz das críticas realizadas por 
Martin (2006) a respeito da concepção de corpo feminino enquanto máquina reprodutiva, na qual a menstruação representaria uma falha de seu propósito. A menstruação ainda traria a tensão pré-menstrual (TPM), que segundo o médico possui efeitos sociais devastadores, incapacitando a mulher de exercer sua função como mãe e como trabalhadora, de modo que o controle hormonal do ciclo menstrual seria duplamente uma forma de devolver ao corpo feminino seu estado de natureza e habilitar a mulher para a vida em sociedade.

Já Rohden analisa a construção recente do diagnóstico da andropausa, com a hipótese de que nas duas últimas décadas vem se configurando um modelo de envelhecimento masculino centrado na dimensão da sexualidade. Enquanto as mulheres já vinham há décadas sendo foco de discursos hormonais, a andropausa traz como novidade que os homens também passam a serem alvos desse discurso que associa hormônios à juventude, sexualidade $\mathrm{e}$ saúde. No processo de construção/reconhecimento, diagnóstico e tratamento dessa nova doença é sintomático que a testosterona ocupou um lugar central. A autora conclui:

\begin{abstract}
Em sintonia com a pregnância do discurso hormonal como fonte explicativa prioritária na medicina desde o século XX, coube à testosterona um papel de destaque já que é o hormônio apresentado como uma espécie de síntese essencial da masculinidade e virilidade. É por meio da configuração de um modelo do aprimoramento externo de si e através do consumo da testosterona que se propagandeará aos homens uma nova capacidade de administração bioquímica do corpo, que lhes garantiria uma fonte inesgotável de renovação da sua própria masculinidade. Pois, como se pôde ver nos discursos que promovem a andropausa, "o homem é mesmo a sua testosterona" (ROHDEN, 2011, p. 192).
\end{abstract}

Esta conclusão é fundamental: o que passa por este discurso é que a pessoa é constituída por seus hormônios, ainda mais por hormônios-chave, associados a dimensões específicas da vida. Assim, o homem com baixa testosterona perderia suas características viris, sendo feminilizado, de modo que a única possibilidade apresentada dentro dessa construção de masculinidade seria a intervenção em suas taxas hormonais. 


\section{HORMÔNIOS ENQUANTO EMOÇÕES ORGÂNICAS}

Os hormônios deram um estatuto orgânico para as emoções, permitindo a intervenção biomédica para o seu controle. Dentre uma grande variedade de tipos, alguns foram incorporados no discurso cotidiano, associados a um modo de emoção e/ou um gênero. Tomando como base matérias jornalísticas, aponto como determinados hormônios aparecem associados às emoções. Uma vez que o objetivo é analisar os discursos construídos pela mídia, ressalto não estar preocupada com um rigor na definição biomédica.

A adrenalina aparece associada ao medo, ao estresse ${ }^{3}$, mas também a uma forma de excitação diante do risco, largamente incorporada no discurso cotidiano em relação a esportes radicais ${ }^{4} \mathrm{e}$ a situações de grande agitação e animação, seu recurso discursivo é usado comumente de forma positiva. A serotonina e a endorfina seriam hormônios do bem-estar, sendo respectivamente o "hormônio da felicidade"5 e o "hormônio do prazer e da paixão", associados à paixão e à atividade sexual e recorrentes nos discursos de praticantes de esportes, em referência a sensação de relaxamento e bem-estar posterior à prática ${ }^{7}$. A associação entre chocolate e a produção de endorfina é utilizada como justificativa para o gosto das mulheres pelo doce, principalmente durante o período da $\mathrm{TPM}^{8}$. Em discursos esportivos, tanto a adrenalina quanto a endorfina podem aparecer categorizadas como "viciantes": o desejo pela adrenalina é que levaria os indivíduos a buscarem situações cada

\footnotetext{
3 Exemplos: matéria da revista Super Interessante, intitulada "Adrenalina: lutar ou amarelar" e matéria do portal Brasil Escola, intitulada "Medo". Disponíveis respectivamente em: https://bit.ly/2Dnh1hZe https:// bit.ly/2zKGQr6. Acesso em: 8 abr. 2017.

4 Exemplo: matéria do site VyaEstelar, do portal UOL, intitulada "Por que esportes radicais atraem tanto?". Disponível em: https://bit.ly/2Vc1bRL. Acesso em: 8 abr. 2017.

5 Exemplo: matéria da revista Veja, intitulada "Cientistas descobrem o gene da felicidade". Disponível em: https://bit.ly/2IKznNy. Acesso em: 8 abr. 2017.

6 Exemplo: matéria do portal Ciência e Cultura, da UFBA, intitulada "Endorfina: o combustível que move a paixão". Disponível em: https://bit.ly/2Iz9cu4. Acesso em: 8 abr. 2017.

7 Exemplo: matéria da revista Veja, intitulada "O barato da corrida”. Disponível em: http://veja.abril.com. br/230408/p_100.shtml. Acesso em: 8 abr. 2017.

8 Exemplo: matéria do site Bolsa de Mulher, intitulada "Hormônio do prazer". Disponível em: https://bit. ly/2Gv6IZY. Acesso em: 8 abr. 2017.
} 
vez mais radicais e a endorfina promoveria a constância da atividade física, pois seus praticantes buscariam constantemente a recompensa de bem-estar advinda da prática, afirmando inclusive experimentarem malefícios - como irritabilidade - quando em "abstinência".

Nesse ponto é importante mencionar o trabalho de Oudshoorn (1994), que aborda o surgimento da endocrinologia e a "invenção" dos chamados "hormônios sexuais" atrelados em ideais de feminilidade e masculinidade. O estrogênio e a testosterona são os hormônios responsáveis pela diferenciação entre os sexos, de modo que ficaram caracterizados como "femininos" ${ }^{10} \mathrm{e}$ "masculinos"11, estando presentes em ambos os sexos com níveis diferenciados. A concentração exacerbada do hormônio do sexo oposto pode ser representada como um perigo de masculinização ou feminilização.

A testosterona é associada às características físicas masculinas, como maior massa muscular, volume de pelos e voz grossa, e também a características comportamentais, como agressividade e maior libido. A menor concentração desse hormônio entre as mulheres opera como justificativa para a noção de que elas seriam menos competitivas e sexuais. Tal concepção parece ser uma permanência do que Laqueur (2001) denominou como modelo do sexo único, no qual mulheres seriam homens menos perfeitos.

Já o estrogênio seria responsável pelas formas arredondadas do corpo feminino, formação das mamas e, aliado à progesterona, pelo ciclo menstrual, cujas alterações cíclicas produziriam alterações de humor, como a TPM. Apesar de concebido como fundamental para as funções biológicas, não possui representação positiva em termos comportamentais, exceto por sua falta no período da menopausa, quando suas taxas declinam, podendo provocar irritabilidade e depressão.

\footnotetext{
Exemplo: matéria da revista Super Interessante, intitulada "Qual é a diferença entre adrenalina e endorfina?”. Disponível em: https://bit.ly/2INCBQh. Acesso em: 8 abr. 2017.

${ }^{10}$ Exemplo: matéria da BBC Brasil, intitulada "Mulher com mais estrogênio é mais bonita, diz pesquisa". Disponível em: https://bbc.in/2VYEQUH. Acesso em: 8 abr. 2017.

${ }^{11}$ Exemplos: matéria do Info Escola, intitulada “Testosterona”. Disponível em: https://bit.ly/2VgrPZK. Acesso em: 8 abr. 2017.
} 
Essas emoções não aparecem mais apenas como obstáculos para o exercício da razão, mas sim conceituadas entre seus aspectos positivos, que devem ser maximizados, e negativos, a serem controlados. Seu cultivo positivo está ligado à atual concepção de saúde que não reside apenas na ausência de doença, mas enquanto bem-estar (MOULIN, 2008), que podemos associar ao que Campbell (2000) denominou por ética romântica, hedonista, que valoriza o prazer do sentir.

\section{OCITOCINA, O HORMÔNIO DO AMOR E DO SAGRADO FEMININO}

Outro hormônio atrelado a uma emoção, tanto no discurso científico quanto do senso comum, é a ocitocina, associada ao amor. Analisarei aqui as representações deste hormônio por ativistas pela humanização do parto, em particular no discurso do médico Michel Odent, de atuação reconhecida no movimento do parto humanizado. Um ponto fundamental das representações nesses discursos é que esse é um grupo que reconhece o dualismo cartesiano e atua no sentido de invertê-lo, questionando a separação entre corpo e mente presente no pensamento e na medicina ocidental.

Grande parte do movimento se assenta na propagação de informações a respeito do parto, que são críticas à medicina tradicional, mas buscam legitimidade na "Medicina Baseada em Evidências"12. Desenvolve-se nesses grupos o que Rose (2013) denominou cidadania biológica ${ }^{13}$. A cidadania biológica é tanto individualizadora quanto coletivizadora, no polo do indivíduo temos os

\footnotetext{
${ }_{12}$ A Medicina Baseada em Evidências (MBE) é um movimento crítico no interior da própria medicina, que aponta que a medicina convencional efetuaria práticas que não teriam embasamento científico. Nas palavras de um dos seus defensores: "MBE se traduz pela prática da medicina em um contexto em que a experiência clínica é integrada com a capacidade de analisar criticamente e aplicar de forma racional a informação científica de forma a melhorar a qualidade da assistência médica. Na MBE, as dúvidas que surgem ao resolver problemas de pacientes são os principais estímulos para que se procure atualizar os conhecimentos" (LOPES, 2000, p. 285).

${ }_{13}$ Conceito criado a fim de abranger todos os projetos de cidadania que ligam suas concepções de cidadãos acerca da existência biológica dos seres humanos (sejam como pessoas, homens e mulheres, famílias, linhagens, comunidades, populações, raças ou espécies).
} 
regimes do cuidado de si e no coletivo o que Rabinow (1999) denominou de biossocialidade, com a criação de coletividades em torno de aspectos corporais relacionados à saúde e doença. Tais definições nos informam particularmente a respeito de como se organiza o ativismo pela humanização do parto:

As formas de cidadania implicadas aqui muitas vezes envolvem conhecimento científico e médico bastante especializado sobre a própria enfermidade: pode-se denominar isso de "biocidadania informacional". Elas implicam formas usuais de ativismo, tais como campanhas por melhor tratamento, fim do estigma, obtenção de acesso a serviços e coisas semelhantes: pode-se chamar isso de "direitos de biocidadania". Mas elas também envolvem novas maneiras de forma cidadania pela incorporação em comunidades ligadas eletronicamente por listas de correio eletrônico e páginas eletrônicas: pode se designar isso de "biocidadania digital" (ROSE, 2013, p. 193).

Dando ênfase ao corpo como instância de saber, defensores da humanização apontam ser um erro não permitir que um hormônio fundamental para o parto atue de sua forma mais natural. Odent define a ação da ocitocina da seguinte forma:

A ocitocina tem ação dupla: ela contrai o útero, possibilitando o nascimento do bebê e a saída da placenta. Por isso é o hormônio mais importante para o nascimento. Além disso, é ela a responsável por contrair os dutos mamários para que o leite materno seja liberado. O hormônio permite que o útero seja contraído também durante o orgasmo. E a ocitocina é responsável até pela ejaculação, já que ela manda uma mensagem para a próstata e vesícula seminal para que se contraiam. Tudo isso é a função mecânica da ocitocina. Agora descobrimos que ela tem um importante papel no âmbito comportamental. E podemos resumir dizendo: qualquer que seja a faceta do amor, a ocitocina está sempre envolvida (MICHEL ODENT, 2013).

Assim, uma das funções principais apontadas para a ocitocina seria propiciar o nascimento e, além disso, ela seria de fundamental importância para a promoção do vínculo entre mãe e filho, por isso defensores da humanização 
reivindicam que os bebês não sejam separados de suas mães logo após o nascimento. As ativistas ainda associam a ausência da produção de ocitocina em cesáreas realizadas fora do trabalho de parto a uma maior probabilidade de depressão pós-parto. É interessante notar como no discurso científico mais amplo, o hormônio responsável pelo amor tem a função primeira de vincular mãe e filho, considerado socialmente o amor em sua forma mais pura e, do ponto de vista biológico, fundamental para a sobrevivência da espécie.

Uma característica particular do discurso de Odent é sua oposição ao termo humanização, afirmando que o principal para um parto é satisfazer as necessidades universais de todos os mamíferos, ou seja, "mamiferizar" o parto, lhe extraindo todos os seus aspectos propriamente humanos e culturais. Apesar da crítica pontual, seu pensamento encontra ecos por todo o movimento. A analogia entre mulheres e demais fêmeas é utilizada como explicação para a fisiologia do parto e a crítica do modelo obstétrico atual. Segundo Odent, a necessidade de se sentir em segurança é fundamental para a mulher em trabalho de parto e é explicada por um antagonismo entre a ocitocina e a adrenalina.

Na floresta, se uma fêmea está para ter um filhote e percebe que há um predador por perto, vai liberar adrenalina, essencial em uma situação de emergência na necessidade de partir para a luta. Essa adrenalina vai bloquear o parto, postergar o nascimento. A segurança é uma necessidade básica para qualquer mamífero. Outra necessidade básica é não se sentir observado (MICHEL ODENT FALA..., 2014).

Esse antagonismo faria da ocitocina um hormônio "tímido", que precisaria de condições de extrema segurança para se manifestar. Segundo o médico, houve uma fase da humanidade em que as mulheres se afastariam do grupo na hora do parto, ficando, porém, próximas de uma mulher experiente ou da própria mãe, que as protegeria da presença de homens ou animais. Para Odent, esta provavelmente seria a origem da parteira: "Nós não temos timidez com relação à nossa mãe e o hormônio aceita aparecer na sua presença. É importante perceber que a parteira é sempre, ou normalmente, uma figura materna" (A OCITOCINA..., 2012). 
Desta constatação vem uma das críticas do médico tanto ao sistema obstétrico hospitalar atual quanto a algumas demandas do movimento pela humanização. Ana, uma doula que esteve presente em uma palestra de Odent em Belo Horizonte em 2008, traz trechos de sua fala que utilizarei aqui. Ela conta que, ao ser perguntado sobre o que achava da Lei do Acompanhante no Brasil (considerada uma grande conquista do movimento), ele respondeu rindo: "Ainda bem que é só uma pessoa”. Em sua concepção, a presença de pessoas demais no parto aumentaria a timidez do hormônio e reduziria o silêncio, que seria fundamental, pois o uso da linguagem acionaria as áreas do cérebro associadas à cultura, que devem ser desligadas para alcançar o estado de natureza ideal, a área mais primitiva do cérebro que é responsável pelo parto, para o parto tal como ele concebe.

Um diferencial ainda maior com as demandas do movimento que é grandemente assentado no ideário do casal grávido, estudado por Salem (2007), é seu apontamento da presença masculina como ainda mais danosa para o parto, incluindo aí a figura do pai do bebê. Uma de suas contribuições fundamentais foi a estruturação na França da maternidade de Pithiviers, na década de 1960, em um formato próximo do que hoje são as casas de parto: um ambiente que se parece mais com uma casa do que com um hospital, em que o atendimento é feito por parteiras. A escolha por estas profissionais está imbuída da concepção de parto enquanto um evento feminino. Na já mencionada palestra, contou uma situação que para ele define seu papel como obstetra:

Em um parto que não evoluía, a parteira o chamou e disse: "Dr, por favor, faça a sua parte". Ele então chamou o marido para fora do quarto, o levou para a cozinha, onde ficaram tomando chá. Incrível, Michel Odent declarou para um auditório lotado, composto por representantes das classes médicas e maternidades, que - fazer a parte do médico é ir para um lugar à parte, acalmar o marido e deixar as coisas com as mulheres (A OCITOCINA..., 2012).

Assim, para ele, a presença do marido é vista como um fator que intervém na tranquilidade da mulher e ainda mais prejudicial seria a concepção do 
momento após o nascimento, como para a criação do vínculo entre pai e filho. Este seria o momento do pico de ocitocina da mulher, que precisaria de um ambiente sem distrações para ocorrer. Não havendo reação hormonal equivalente no homem, este momento deveria ficar reservado a ela.

Uma distinção fundamental em relação à ocitocina se encontra na oposição natureza/cultura. Enquanto ela é valorizada como produto do próprio corpo da mulher, é execrada em sua variação sintética, entendida pelas ativistas e profissionais ligados a humanização do parto como um intervenção desnecessária. A ocitocina sintética é vista como um recurso utilizado por médicos alheios às boas práticas propagadas pelo movimento e afeitos a uma obstetrícia mais clássica e desatualizada, que busca intervir no processo de modo a adequar a temporalidade do parto aos padrões pré-estabelecido, em oposição a respeitar o tempo do trabalho de parto (MENDONÇA, 2018).

O discurso do ativismo pela humanização do parto é plural, como demonstrado Odent discorda e possui críticas à forma como ela vem sendo praticada, do mesmo modo que ativistas podem ter críticas a aspectos do ideário de Odent, como me disse uma mulher que entrevistei, que considerava seu discurso demasiado radical e mesmo fora da realidade, principalmente no que diz respeito a não vacinação das crianças (outro ponto que ele defende, no sentido de uma aproximação com a natureza). Porém, apesar das discordâncias, ele é um nome influente para o movimento, seus livros são recomendados e citados por diversos médicos, profissionais e ativistas da humanização. Sua presença frequente no Brasil faz com que ele seja personagem constante em palestras e documentários sobre o tema e sua frase "para mudar o mundo, primeiro é preciso mudar a forma de nascer" estampa camisetas e adesivos do movimento. E para a discussão que proponho neste trabalho, a respeito da ocitocina, a centralidade atribuída pelo médico ao hormônio parece ser amplamente difundida.

Assim, daqui em diante analisarei um aspecto da representação da ocitocina feito pelo movimento que me parece ser particular dentro dos demais discursos sobre os hormônios. Retomando a discussão de Strathern (1999), o discurso sobre a ocitocina se refere a uma substância que é produzida no 
próprio corpo em determinadas situações específicas, que se busca controlar (ambiente seguro e silencioso) e que age "produzindo" o amor/vínculo entre mãe e filho. Ou seja, temos um sistema de agência-substância-agência. Este sistema pode ser pensado também para alguns hormônios que possuem representações semelhantes no senso comum, como a adrenalina e a endorfina: uma pessoa pode praticar um esporte radical buscando produzir adrenalina, que o fará se sentir destemido, ou pode praticar um esporte almejando a sensação de relaxamento posterior provocada pela endorfina.

O sistema de substância e agência pode ser mais uma vez complexificado na medida em que alguns hormônios são caracterizados como contagiantes, como é o caso da adrenalina e da ocitocina. Neste caso teríamos então uma agência que produz uma substância, que ao se desdobrar novamente em agência produziria a mesma substância em outras pessoas. Uma busca no Google pelo termo "adrenalina contagiante" resulta em mais de 100 mil resultados, se referindo principalmente à "energia" do público em festas e shows. Já a ocitocina também é referida como contagiante e me parece um discurso mais sistemático, com particularidades que merecem ser exploradas, pois se enraízam no ideário da humanização como um todo.

As referências à ocitocina como contagiante são múltiplas. Normalmente aparecem no discurso de mulheres profissionais que atuam na assistência ao parto. Ao comemorar um parto bem sucedido elas costumam contar o longo período que passaram assistindo ao parto, que muitas vezes as pega de surpresa e que ao final estão cansadas, porém felizes e "ocitocinadas". Em redes sociais encontrei fotos tiradas após partos com legendas como "todas lindas de ocitocina", aludindo a um possível efeito embelezador do hormônio. Em uma delas constavam a doula, a parturiente e uma menina de cerca de dez anos de idade. A ocitocina é vista como contagiando todas as mulheres presentes no momento do parto e esta é uma característica que a distingue da representação contagiante da adrenalina: ela contagia somente mulheres.

A ocitocina também é utilizada como adjetivo para se referir ao movimento pela humanização do parto em si, à sensação que aquelas mulheres experimentam ao estarem juntas defendendo algo em que acreditam. Assim o bloco 
de carnaval organizado pelas ativistas é definido como o mais "ocitocinado" de todo o carnaval e uma ativista, ao assistir ao filme $O$ renascimento do parto (2013) em sua pré-estreia, se diz: "totalmente mexida, intrigada, ocitocinada (cheia de ocitocina), feliz" (VALENTE, 2013).

\section{CONCLUINDO (E PROBLEMATIZANDO)}

Boa parte do ideário do movimento está assentado nesta noção de um sagrado feminino, uma natureza feminina que é compartilhada pelas mulheres e precisa ser resgatada. Como desdobramentos disso temos as figuras das parteiras e doulas, que são essencialmente valorizadas pelos elementos femininos que trazem para o parto.

Uma situação que vivenciei em campo é exemplar dessa noção difundida no meio de que existe uma essência natural feminina que se fortalece na conexão com outras mulheres. Era o encerramento de um seminário sobre parto humanizado e foi realizada uma dinâmica na qual apenas as mulheres presentes formaram uma roda e, sob a liderança de uma delas, executaram danças dos "índios brasileiros". Demos as mãos, giramos e balançamos nossos corpos juntas. Ao final a mulher que estava ao meu lado me disse: "Isso é fantástico! Fazem 11 meses que eu não menstruo e sei que amanhã a minha menstruação vai descer!”.

O artigo de Alzuguir e Nucci (2015) aborda um grupo que está relacionado ao das ativistas pelo parto humanizado, as "mães mamíferas", que defendem a denominada "maternidade ativa"14. As autoras têm como objetivo problematizar os argumentos que se ancoram em uma noção de natureza feminina universal, buscando propor outras possibilidades discursivas e de agenciamento que não reforcem a equação mulher natureza.

\footnotetext{
14 "A maternidade ativa ou consciente se refere tanto à adoção de orientações científicas sobre o cuidado com os bebês, como à tomada de consciência sobre a capacidade de fazer escolhas em torno da maternagem (POMBO, 2013). Dentre os diversos pontos enfatizados pelas 'mamíferas', destaca-se a defesa do parto natural e humanizado (domiciliar e hospitalar), a amamentação 'prolongada' (durante dois anos ou mais) e em livre demanda (sem horários rígidos pré determinados, isto é, sempre que o bebê solicitar o seio)" (ALZUGUIR; NUCCI, 2015).
} 
Apontam que um dos paradoxos presentes nesse meio é o de que a desmedicalização do corpo feminino se apoia nas "evidências científicas", buscando nelas o respaldo para as práticas de parto e amamentação. Os estudos acionados dão legitimidade à noção premente no grupo de que a natureza do corpo feminino é "sábia e perfeita", cabendo à mulher reconhecê-la e a deixar agir. $\mathrm{Na}$ articulação entre essa percepção da natureza feminina e as "evidências científicas", a ocitocina ocupa um lugar de destaque, significando para aquelas mães a confirmação de sua natureza mamífera e reforçando no imaginário social a noção de "instinto materno".

Com o suporte nos trabalhos dos campos de gênero e ciência (BADINTER, 1985; LAQUEUR, 2001; SCHIEBINGER, 1986, 1998), as autoras destacam o caráter social e político do processo de naturalização da reprodução feminina pelos discursos científicos a partir do Iluminismo, no qual a ênfase no determinismo biológico foi acionada de modo a excluir as mulheres dos ideais de igualdade e liberdade, sem contradizer o ideário.

Badinter (1985) se dedica a atacar as bases do argumento diferencialista fundadas na noção de natureza e instinto por meio da pesquisa histórica a respeito do recurso massivo às amas de leite nos séculos XVII e XVIII na França, generalizado a todas as camadas sociais urbanas. Mesmo resultando em alta mortalidade infantil conhecida, as mulheres da época continuaram a adotar a prática até o período pós-revolução francesa, no qual a construção do papel de mãe-cuidadora e as campanhas de aleitamento materno foram eficazes em condenar a conduta. Segundo Schiebinger (1998), nesse período, as representações das diferenças biológicas entre homens e mulheres foram exacerbadas, de modo a excluí-las da Declaração de Direitos do Homem e do Cidadão e relegá-las ao espaço doméstico e materno. Para Badinter, o exame desse momento histórico é revelador de que o amor materno não se trata de um instinto natural - uma vez que as mães se afastavam de seus filhos por vontade própria pouco após o nascimento, retomando-os alguns anos depois, apenas para pouco conviverem com eles antes de enviá-los para alguma instituição de ensino -, mas sim uma construção social histórica que será reafirmada pelas políticas higienistas e pela psicanálise. 
Tal noção de natureza perfeita pode ser extremamente opressora para as mulheres que, por motivos que vão muito além de suas capacidades individuais, não conseguem parir naturalmente ou enfrentam dificuldades na amamentação (MENDONÇA, 2015). Corroborando com a análise de Pombo (2013), Alzuguir e Nucci indagam (2015, p. 234):

“[...] se essas práticas [de maternagem] eram escolhas, por que colocá-las como um destino biologicamente determinado?” (POMBO, 2013, p. 35). Daí o questionamento subsequente: se as mães que não aderem às práticas mamíferas preconizadas não seriam por isso condenadas ao status de mães "desnaturadas".

As autoras concluem que ao vincular a maternidade a uma noção de instinto, ela é pensada de forma individual, que só pode ser plenamente realizada por aquelas que possuem recursos financeiros e suporte de terceiros, escapando assim a potência política de pensá-la coletivamente, em termo de políticas públicas que apoiassem as mães no cuidado na primeira infância, ou, no caso do parto, uma demanda pela ampliação no sistema de saúde público.

Aqui as críticas às tentativas de superação do dualismo cartesiano coincidem tanto na antropologia como no movimento pela humanização do parto. Como Citro (2010) destaca, as tentativas por colocar o corpo em cena para análise, por vezes, pesaram para o outro lado da balança, apenas invertendo a hierarquia, sem conseguir abolir o dualismo. De forma semelhante, Tornquist (2002) denomina como armadilhas da humanização do parto o discurso em torno da essência feminina, por meio da noção da existência de um sagrado feminino. Sua associação com a natureza - além de não provocar uma ruptura com o pensamento biomédico clássico - reproduz categorias como a de instinto materno. Ao colocar o corpo e sua natureza no topo da hierarquia, acaba se oprimindo diversas outras formas de ser mulher. 


\section{REFERÊNCIAS}

1. A OCITOCINA é um hormônio tímido, por Michel Odent. Bibliografia da doula, [s. l.], 3 dez. 2012. Disponível em: http://bit.ly/2YaP8lw. Acesso em: 8 abr. 2017.

2. ALZUGUIR, Fernanda Vecchi; NUCCI, Marina Fischer. Maternidade mamífera? Concepções sobre natureza e ciência em uma rede social de mães. Mediações, Londrina, v. 20, n. 1, p. 217-238, jan.-jun. 2015.

3. AZIZE, Rogério. Notas de um "não-prescritor": uma etnografia entre os estandes da indústria farmacêutica no congresso brasileiro de psiquiatria. In: MALUF, Sônia; TORNQUIST, Carmen Susana. Gênero, saúde e aflição: abordagens antropológicas. Florianópolis: Letras Contemporâneas, 2010.

4. BADINTER, Elisabeth. Um amor conquistado: o mito do amor materno. Rio de Janeiro: Nova Fronteira, 1985.

5. BONET, Octavio. Saber e sentir: uma etnografia da aprendizagem da biomedicina. Rio de Janeiro: Editora Fiocruz, 2004.

6. BOURDIEU, Pierre. Esboço de uma teoria da prática. In: ORTIZ, Renato (org.). Pierre Bourdieu: Sociologia. São Paulo: Ática, 1983. p. 46-81.

7. BUTLER, Judith. Problemas de gênero. Rio de Janeiro: Civilização Brasileira, 2003.

8. CAMPBELL, Colin. A ética romântica e o espírito do consumismo moderno. Rio de Janeiro: Rocco, 2000.

9. CITRO, Silvia. La antropología del cuerpo y los cuerpos en el mundo. In: CITRO, Silva (coord.). Cuerpos plurales: antropología de y desde los cuerpos. Buenos Aires: Biblos, 2010.

10. CSORDAS, Thomas. Corpo/Significado/Cura. Porto Alegre, Editora UFRGS, 2008.

11. ELIAS, Norbert. O processo civilizador 2: formação do Estado e civilização. São Paulo: Zahar, 1994.

12. FOUCAULT, Michel. Microfísica do poder. Rio de Janeiro: Graal, 1982.

13. LAQUEUR, Thomas. Inventando o sexo: corpo e gênero dos gregos a Freud. Rio de janeiro: Relume-Dumará, 2001.

14. LATOUR, Bruno. Reagregando o social: uma introdução à teoria do Ator-Rede. Salvador: Edufba, 2012.

15. LATOUR, Bruno; WOOLGAR, Steve. A vida de laboratório: a produção dos fatos científicos. Rio de Janeiro: Relume-Dumará, 1997. 
16. LOPES, Antonio Alberto. Medicina Baseada em Evidências: a arte de aplicar o conhecimento científico na prática clínica. Revista da Associação Médica Brasileira, São Paulo, v. 46, n. 3, p. 285-288, 2000.

17. MALUF, Sônia Weidner. Sofrimento, "saúde mental" e medicamentos: regimes de subjetivação e tecnologias do gênero. In: TORNQUIST, Carmen Susana; COELHO; Clair Castilhos; LAGO, Mara Coelho de Souza; LISBOA, Teresa Kleba (org.). Leituras de resistência: corpo, violência e poder. Florianópolis: Mulheres, 2009. p. 145-161. v. II.

18. MANICA, Daniela Tonelli. A desnaturalização da menstruação: hormônios contraceptivos e tecnociência. Horizontes Antropológicos, Porto Alegre, v. 17, n. 35, 2011.

19. MARTIN, Emily. A mulher no corpo: uma análise cultural da reprodução. Rio de Janeiro: Garamond, 2006.

20. MAUSS, Marcel. As técnicas do corpo. In: MAUSS, Marcel. Sociologia e Antropologia. São Paulo: Cosac Naify, 2003.

21. MENDONÇA, Sara Sousa. Mudando a forma de nascer: agência e construções de verdades entre ativistas pela humanização do parto. 2013. Dissertação (Mestrado em Antropologia) - Universidade Federal Fluminense, Niterói, 2013.

22. MENDONÇA, Sara Sousa. Modelos de assistência obstétrica concorrentes e ativismo pela humanização do parto. Civitas, Porto Alegre, v. 15, n. 2, p. 250-271, abr.-jun. 2015.

23. MENDONÇA, Sara Sousa. Parir na Maria Amélia: uma etnografia dos dilemas, possibilidades e disputas da humanização em uma maternidade pública carioca. 2018. Tese (Doutorado em Antropologia) - Universidade Federal Fluminense, Niterói, 2018.

24. MERLEAU-PONTY, Maurice. Fenomenologia da percepção. São Paulo: Martins Fontes, 2011.

25. MICHEL ODENT. Pais\&Filhos, São Paulo, 9 ago. 2013. Disponível em: https:// bit.ly/2IP3iV0. Acesso em: 8 abr. 2017.

26. MICHEL ODENT FALA sobre parto, nascimento e ocitocina. Parto com Amor, [s. l.], 3 nov. 2014. Disponível em: https://bit.ly/2XAAPGG. Acesso em: 8 abr. 2017.

27. MOULIN, Anne Marie. O corpo diante da Medicina. In: CORBIN, Alain; COURTINE, Jean-Jacques; VIGARELLO, Georges. História do corpo. Petrópolis: Vozes, 2008. v. 3.

28. OUDSHOORN, Nelly. Beyond the natural body: an archaeology of sex hormones. London: Routledge, 1994. 
29. POMBO, Carolina. A mãe e o tempo: ensaio da maternidade transitória. Rio de Janeiro: Memória Visual, 2013.

30. RABINOW, Paul. Antropologia da razão. Rio de Janeiro: Relume-Dumará, 1999.

31. ROHDEN, Fabíola. Império dos hormônios e a construção da diferença entre os sexos. História, Ciência, Saúde, Manguinhos, v. 15, Supl., p. 133-152, 2008.

32. ROHDEN, Fabíola. "O homem é mesmo a sua testosterona": promoção da andropausa e representações sobre sexualidade e envelhecimento no cenário brasileiro. Horizontes Antropológicos, Porto Alegre, ano 17, n. 35, p. 161-196, jan.-jun. 2011.

33. ROSE, Nikolas. A política da própria vida: biomedicina, poder e subjetividade no século XXI. São Paulo: Paulus, 2013.

34. RUSSO, Jane. Do desvio ao transtorno: a medicalização da sexualidade na nosografia psiquiátrica contemporânea. In: PISCITELLI, Adriana; GREGORI, Maria Filomena; CARRARA, Sérgio (orgs.). Sexualidade e saberes: convenções e fronteiras. Rio de Janeiro: Garamond, 2004.

35. SALEM, Tania. O casal grávido: disposições e dilemas da parceria igualitária. Rio de Janeiro: Editora FGV, 2007.

36. SCHIEBINGER, Londa. Skeletons in the closet: the first illustrations of the female skeleton in eighteenth-century anatomy. Representations, Berkeley, n. 14, p. 42-82, 1986.

37. SCHIEBINGER, Londa. Mamíferos, primatologia e sexologia. In: PORTER, Roy; TECH, Mikolas. Conhecimento sexual, ciência sexual: história das atitudes em relação a sexualidade. São Paulo: Editora Unesp, 1998. p. 219-246.

38. STRATHERN, Andrew. Body thoughts. Ann Arbor: University of Michigan Press, 1999.

39. TORNQUIST, Carmen Susana. Armadilhas da Nova Era: natureza e maternidade no ideário da humanização do parto. Estudos Feministas, Santa Catarina, v. 10, n. 2, p. 483-492, 2002.

40. USECHE ALDANA, Bernardo. Medicalización, erotismo y diversidad sexual: una crítica sexológica al DSM-IV-TR (I parte). Sexología Integral, [s. l.], v. 2, n. 1, p. 36-42, 2005.

41. VALENTE, Carol. Uma semana de renascimentos (uma opinião sobre o filme O Renascimento do Parto). Parir-se ao parir, [s. l.], 10 ago. 2013. Disponível em: https://bit.ly/2XA2042. Acesso em: 8 abr. 2017. 